\title{
SIDONIE: A gateway for visual double stars studies
}

\author{
D. Le Contel, J.-C. Valtier, and D. Bonneau \\ Observatoire de la Côte d'Azur, Département Fresnel, BP 4229, 06304 Nice Cedex 4, France \\ Received 19 December 2000 / Accepted 22 June 2001

\begin{abstract}
A database on visual binaries is presented. It contains measurements on 12750 visual binaries with less than $2^{\prime \prime}$ of separation or with large proper motion north of -10 degrees of declination. It contains also bibliographic references and published orbits for 851 stars. The SIDONIE database is implemented on the Web and allows astronomers to prepare new observations, find data to calculate new orbits or obtain statistical information on the stars in the database.
\end{abstract}

Key words. astronomical data bases: miscellaneous - stars: binaries: general - stars: binaries: visual

\section{Introduction}

A database concerning Visual Double Stars should, on one hand, allow for the preparation of observational programs and, on the other hand, provide the necessary data for calculating orbits, the knowledge of which is fundamental to the astrophysical study of double or multiple stars. These two elements are prerequisites for the nature of the data to be provided.

Until now, only two large databases on Visual Double Stars exist: 1) The USNO (United States Naval Observatory) which links the Washington visual catalog of Double Stars (WDS) with the Fifth Catalog of orbits of Visual Binary Stars. The WDS (Worley 1997) consists of 84300 double stars and includes nearly 550000 measurements dating back to the early 1700 's. The part which is accessible on-line, notably from the "Centre de Données Stellaires de l'Observatoire de Strasbourg" (CDS) has identifiers of each system as well as information on the period covered by the observations and the number of measurements available and a list of references concerning the discoverers. The WDS was originally conceived to allow the preparation of observation programs. Nevertheless, individual measurements can be obtained on demand from USNO for a reasonable number of objects. The Fifth Catalog of Orbits of Visual Binaries contains the parameters of 1465 orbits for 1430 systems and their references. 2) The CHARA database gives access to the Third Catalog of Interferometric Measurements of Binary Stars (Hartkopf 2000). This base, accessible on-line via the Internet by way

Send offprint requests to: D. Le Contel,

e-mail: danielle@obs-nice.fr of the "Double Star Library" at the USNO, contains the observation of 25076 double and multiple stars, including measurements made by interferometric techniques, adaptive optic and lunar occultation, as well as measurements provided by the astronomic satellite HIPPARCOS.

In this article, the database SIDONIE (Site Informatique des étoiles DOubles de NIcE) will be described. Section 2 gives its origins. The technical description concerning the choice of information and the system of long-distance interrogation of this database is in Sect. 3. The scientific contents of the SIDONIE database is examined in Sect. 4.

\section{SIDONIE's origins}

In 1972 P. Couteau created the Centre des Etoiles Doubles de Nice (The Double Star Center of Nice) where all the data on couples discovered in Nice as well as the measurements for visual close couples (less than $2^{\prime \prime}$ separation) or large proper motion stars located north of -10 degrees declination are stored on hand-written cards. The file, containing 12700 visual couples, includes all the measurements obtained since 1927. It is complemented by another file giving published orbits since 1877 for 851 of these objects. This hand-written project, consisting of more than 20000 individual cards, is a tool used to calculate new orbits and to optimize the preparation of observations in relation to existing data. After the retirement of P. Couteau, the decision was made to protect and save this patrimony and make it available to double stars observers. Three groups immediately demonstrated their interest in this project: the Department 


\begin{tabular}{|c|c|c|c|c|c|c|}
\hline $2145.4 \mathrm{~N}$ & & 2147 & $N_{1}$ & 704 & 1.50 .2 & \\
\hline $\operatorname{cou}^{228601}$ & & $54^{\circ} \cdot 2$ & & & & \\
\hline $0 \begin{array}{r}14 \\
5.5-72\end{array}$ & $\begin{array}{l}1966.73 \\
1960.74\end{array}$ & $\begin{array}{l}59.0 \\
54.7\end{array}$ & $\begin{array}{l}0.33 \\
0.37\end{array}$ & $\mid \begin{array}{l}\text { VB } \\
c\end{array}$ & & \\
\hline If 8334 HD2076052 & $\begin{array}{l}196,1.53 \\
4961.60\end{array}$ & $\begin{array}{l}593 \\
63.0\end{array}$ & $\begin{array}{l}0.25 \\
0.31\end{array}$ & 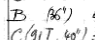 & $6.1-6.8$ & 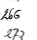 \\
\hline$\pi$ to & 1961.73 & 66.4 & $\begin{array}{l}0.37 \\
0.33\end{array}$ & $V_{V B}$ & & \\
\hline$r=\| 012 \pm 6$ & $\begin{array}{l}1966.2 .94 \\
1962.84\end{array}$ & $\begin{array}{l}63.1 \\
74.7\end{array}$ & & & & \\
\hline 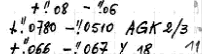 & $\begin{array}{l}1965.78 \\
1963.31\end{array}$ & $\begin{array}{l}\text { simple } \\
\text { pes rond }\end{array}$ & $60 ?$ & $\mid \begin{array}{ll}c & (38) \\
c & (38)\end{array}$ & & \\
\hline 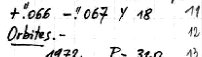 & 1964.78 & simple & $C B$ & $c(38)$ & & \\
\hline 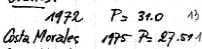 & $\begin{array}{l}1964.85 \\
1965.72 \\
195\end{array}$ & 59.20 & 0.45 & wor 183$)$ & & \\
\hline 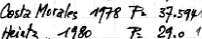 & $\left\{\begin{array}{l}1965.75 \\
5\end{array}\right.$ & roude & 0.13 & $c(38)$ & & \\
\hline $\begin{array}{l}1.675 \\
6.11\end{array}$ & 1966.50 & non & $=7$ & Me. & & \\
\hline & & 208.6 & 0.23 & $c(38)$ & & \\
\hline fule 6075 & $\begin{array}{l}1996.87 \\
1966.872\end{array}$ & $\begin{array}{l}210.6 \\
214.1\end{array}$ & $\begin{array}{l}0.23 \\
0.27\end{array}$ & $\sqrt{61}$ & & \\
\hline
\end{tabular}

Fig. 1. Hand-written card containing datas on the star COU 14.

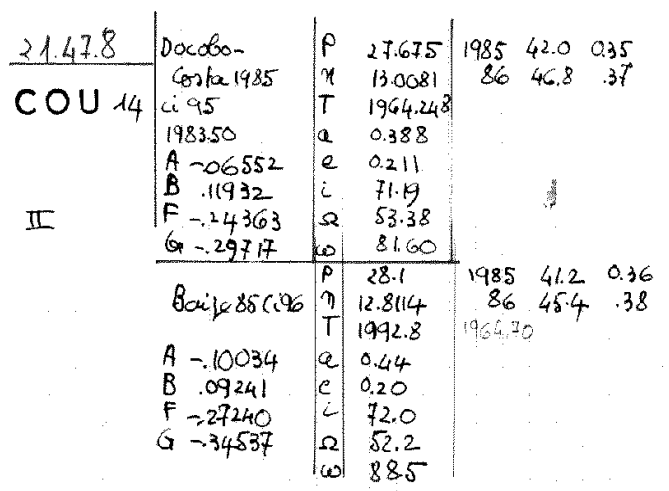

Her

Fig. 2. Hand-written card of the orbital elements of the star COU 14.

CERGA of the OCA for applications related to the HIPPARCOS mission, E. Oblak, the astronomer responsible for the Besancon double and multiple stars database (http://bdb.obs-besancon.fr/bdb/), and the double stars observers in Nice. The natural solution was to create a computer-based support for the manuscript cards. Figure 1 shows, as an example, a hand-written card of measurements of the star COU 14 .

Figure 2 shows the card concerning some of the orbital parameters published for this star.

\section{Technical description of SIDONIE}

The goal of safeguarding these data led to the choice of creating this database on a PC type computer using a program destined for business databases: Microsoft ACCESS. The hand-written notes contained large amounts of data, which were sometimes redundant, or out of context, therefore it was necessary to select the information that was to be put into the computer database. In order to identify stars, the deliberate choice was made to not include existing identifications easily accessible in other catalogs. Our goal is to provide a maximum of detail on measurements. Retained in the database are: equatorial coordinates (J2000); BD, ADS, and HIP names and numbers and the magnitude of the components and their spectral
SIDONIe - Identifications and measurements

\begin{tabular}{|c|c|c|c|c|c|c|c|c|}
\hline & $\begin{array}{r}\text { On the obj } \\
\text { COU } 14\end{array}$ & ject & $\begin{array}{l}\text { BD \# } \\
16.4612\end{array}$ & ADS & $\begin{array}{l}S \# \\
\quad H \\
10\end{array}$ & ITP \# & & $\begin{array}{l}\text { pectral type } \\
\text { F2 }\end{array}$ \\
\hline & $\begin{array}{r}\text { Alpha } 200 \\
21 \text { h } 50.2 \text { r }\end{array}$ & & $\begin{array}{c}\text { Delta } 2000 \\
17^{\circ} 18^{\prime}\end{array}$ & $\begin{array}{r}\mathrm{mag} \\
05\end{array}$ & & $\begin{array}{l}\operatorname{lag} 2 \\
07.2\end{array}$ & Calc & $\begin{array}{l}\text { culated Orbit? } \\
\text { YES }\end{array}$ \\
\hline Date & Angle & Separ. & Nights & Code & Instr. & Dim. & Ref. & Notes \\
\hline 1959.89 & 54.2 & 00.36 & 3 & $\operatorname{coU}$ & L & 38 & 240 & \\
\hline 1960.73 & 59.0 & 00.33 & 5 & VBS & $\mathrm{T}$ & & 302 & \\
\hline 1960.74 & 54.7 & 00.37 & 3 & $\mathrm{COU}$ & L & 38 & 251 & \\
\hline 1961.53 & 59.3 & 00.25 & 4 & B & $\mathrm{L}$ & & 266 & \\
\hline 1961.60 & 63.0 & 00.31 & 3 & $\mathrm{COU}$ & T & 91 & 273 & $\mathrm{dm}=<1$ \\
\hline 1961.73 & 66.4 & 00.33 & 4 & VBS & $T$ & & 302 & \\
\hline 1962.67 & 63.1 & 00.22 & 3 & $\mathrm{COU}$ & $\mathrm{L}$ & 38 & 284 & \\
\hline 1962.84 & 74.7 & 00.25 & 2 & VBS & $\mathrm{T}$ & & 302 & \\
\hline 1963.78 & & 00. & 1 & $\mathrm{COU}$ & L & 38 & 290 & pas vue double \\
\hline 1963.81 & & 00. & 1 & $\mathrm{COU}$ & L & 38 & 290 & trop serrée \\
\hline 1964.78 & & 00 . & 2 & $\mathrm{COU}$ & L & 38 & 300 & pas vue double \\
\hline 1964.840 & 156.3 & 00.13 & 1 & WOR & L & & 346 & \\
\hline 1964.85 & & 00. & 1 & WOR & L & & 346 & pas vue double \\
\hline 1965.72 & 59.2 & 00.45 & 1 & MLR & L & 83 & 334 & \\
\hline 1965.75 & & 00. & 2 & $\mathrm{COU}$ & L & 38 & 300 & pas vue double \\
\hline 1965.78 & 199.7 & 00.13 & 2 & WOR & T & & 346 & \\
\hline 1966.50 & & 00. & I & MLR & L & 83 & 334 & pas vue double \\
\hline 1966.68 & 202.2 & 00.23 & 1 & MLR & L & 83 & 334 & \\
\hline 1966.72 & 208.6 & 00.23 & 4 & $\mathrm{COU}$ & L & 38 & 304 & \\
\hline 1966.87 & 212.6 & 00.23 & 2 & WOR & T & & 346 & \\
\hline 1966.872 & 214.1 & 00.27 & 2 & WAK & $T$ & & 331 & \\
\hline
\end{tabular}

Fig. 3. Web page obtained by querying SIDONIE for measurements of COU 14.

types. The parameters describing each measurement are: the date (fraction of the year), the position angle (degree), the angular separation (arc seconds), the number of measurements, the observer code, the type of instrument used (lunette or telescope, diameter in centimeters or inches), the reference of the publication and notes (observation technique, quality of the measurement). The orbits are described by the classic elements: period ( $P$ in years), periastron passage date ( $T$ in years), eccentricity $(e)$, angular semimajor-axis ( $a$ in arcsec), inclination ( $i$ in degrees) node position angle ( $\Omega$ in degrees), periastron node angle ( $\omega$ in degrees), the author of the calculation and the reference of the publication. The main interest of this database being its interactivity, considerable work was done with regard to the extraction of information and on the choice of the types of interrogatory modes in accordance with the observers. Finally the database was interfaced with the Web so that it could be interrogated and exploited at a distance. A copy of the file was also sent to the "Centre de Données Stellaires" (CDS) of the Strasbourg Observatory (http://cdsweb.u-strasbg.fr/) who is in charge of establishing links between SIDONIE and the different catalogs that already exist. The SIDONIE Website address is:

http://sidonie.obs-nice.fr/

\section{The scientific contents of SIDONIE}

Today, SIDONIE contains 12750 objects and 162000 individual measurements. The first measurement dates back to 1773 for the star STF 2644 (ADS 13506). There are currently 851 calculated orbits, the first dating back to 1877 for the star STF 2729 (ADS 14360). The access to SIDONIE on the Web allows interrogation by object, which gives access to the individual measurements, the orbits and the references. Figure 3 shows the result of an 


\section{SIDONle - Orbit Parameters}

\begin{tabular}{|c|c|c|c|c|c|c|c|c|c|c|c|}
\hline \multicolumn{3}{|c|}{\begin{tabular}{|c|} 
On the object \\
COU 14 \\
Alphas 2000 \\
$21 \mathrm{~h} 50.2 \mathrm{mn}$ \\
\end{tabular}} & \multicolumn{2}{|c|}{$\begin{array}{c}\mathrm{BD} \# \\
16.4612 \\
\text { Delta } 2000 \\
17^{\circ} 18^{\circ} \\
\end{array}$} & \multirow{2}{*}{$\begin{array}{c}\text { ADS \# } \\
\begin{array}{c}\operatorname{mag} 1 \\
05.5\end{array} \\
T\end{array}$} & \multicolumn{2}{|c|}{\begin{tabular}{|c|} 
FIIP \# \\
107788 \\
$\operatorname{mag} 2$ \\
07.2 \\
\end{tabular}} & \multicolumn{3}{|c|}{$\begin{array}{c}\text { Spectral type } \\
\text { F2 } \\
\text { Calculated Orbit? } \\
\text { Yes }\end{array}$} & \multirow[b]{2}{*}{ Note } \\
\hline & & $\begin{array}{ll}\text { Ref. } \\
\end{array}$ & P & $n$ & & a & e & $i$ & 0 & $\bar{w}$ & \\
\hline HEINTZ & 1972 & AJ 78 & 31.0 & 11.6129 & 1964.6 & 0.400 & 0.29 & 69.5 & 51.3 & 90.0 & \\
\hline $\begin{array}{l}\text { COSTA- } \\
\text { MORALES }\end{array}$ & 1975 & cir 64 & 8 & 813.086 & 1965.490 & 0.387 & 0.194 & 70. & 52.0 & 100.954 & \\
\hline $\begin{array}{l}\text { COSTA- } \\
\text { MORALES }\end{array}$ & 1978 & cir 75 & 37.5949 & 49.575 & 1965,101 & 0.387 & 0.433 & 69.00 & 50.5 & 101.024 & \\
\hline HEINTZ & 1980 & cir 82 & 29.01 & 12.4138 & 1964.7 & 0.396 & 0.24 & 71.7 & 51.9 & 90 & \\
\hline BAIZE & 1985 & cir 96 & 28.1 & 12.8114 & 1992.8 & 0.44 & 0.20 & 72.0 & 52.2 & 88.5 & \\
\hline $\begin{array}{l}\text { DOCOBO- } \\
\text { COSTA }\end{array}$ & 1985 & cii & $27.675 \mid$ & 5:13.0081 & 1964.248 & 0.388 & 0.211 & 71.19 & 53.38 & 81.60 & \\
\hline & & & & & & & & & & & \\
\hline
\end{tabular}

Fig. 4. Web page obtained by querying SIDONIE for orbit parameters of COU 14.

\begin{tabular}{|c|c|c|c|c|c|}
\hline \multicolumn{2}{|r|}{$\begin{array}{l}\text { On the object } \\
\text { COU } 14\end{array}$} & $\begin{array}{c}\text { BD \# } \\
16.4612\end{array}$ & ADS \# & $\begin{array}{l}\text { HIP \# } \\
107788\end{array}$ & $\begin{array}{l}\text { Spectral type } \\
\text { F2 }\end{array}$ \\
\hline \multicolumn{2}{|r|}{$\begin{array}{l}\text { Alpha } 2000 \\
21 \text { h } 50.2 \mathrm{mn}\end{array}$} & $\begin{array}{c}\text { Delta } 2000 \\
17^{\circ} 18^{\prime}\end{array}$ & $\begin{array}{l}\operatorname{mag} 1 \\
05.5\end{array}$ & $\begin{array}{c}\operatorname{mag} 2 \\
07.2\end{array}$ & $\begin{array}{c}\text { Calculated Orbit? } \\
\text { Yes }\end{array}$ \\
\hline Ref. & \multicolumn{3}{|c|}{ Author } & \multicolumn{2}{|r|}{ Journal } \\
\hline 240 & \multicolumn{3}{|l|}{ Couteau $\mathrm{P}$. } & \multicolumn{2}{|c|}{1960 JO 431} \\
\hline 251 & \multicolumn{3}{|l|}{ Couteau $\mathrm{P}$. } & \multicolumn{2}{|c|}{1961 JO 4441} \\
\hline 266 & \multicolumn{3}{|c|}{ Bos W. H. van den } & \multicolumn{2}{|c|}{1962 AJ 67141} \\
\hline 273 & \multicolumn{3}{|l|}{ Couteau $P$. } & \multicolumn{2}{|c|}{$1962 \mathrm{JO} 45225$} \\
\hline 284 & \multicolumn{3}{|l|}{ Couteau $\mathrm{P}$. } & \multicolumn{2}{|c|}{$1963 \mathrm{JO} 46155$} \\
\hline 290 & \multicolumn{3}{|l|}{ Couteau $\mathrm{P}$. } & \multicolumn{2}{|c|}{$1964 J 047229$} \\
\hline 300 & \multicolumn{3}{|l|}{ Couteau $P$. } & \multicolumn{2}{|c|}{$1966 \mathrm{JO} 49341$} \\
\hline 302 & \multicolumn{3}{|c|}{ Van Biesbroeck G. } & \multicolumn{2}{|c|}{1965 CLPL 351} \\
\hline 304 & \multicolumn{3}{|l|}{ Couteau P. } & \multicolumn{2}{|c|}{1967 JO 5041} \\
\hline 317 & \multicolumn{3}{|l|}{ Couteau P. } & \multicolumn{2}{|c|}{1968 JO 51337} \\
\hline 318 & \multicolumn{3}{|l|}{ Morel P. J. } & \multicolumn{2}{|c|}{1968 JO 51349} \\
\hline 330 & \multicolumn{3}{|l|}{ Couteau P. } & \multicolumn{2}{|c|}{1970 A\&AS 351} \\
\hline 331 & \multicolumn{3}{|l|}{ Walker R. L. jr } & \multicolumn{2}{|c|}{1969 PUSNO 122} \\
\hline 332 & \multicolumn{3}{|l|}{ Morel P. J. } & \multicolumn{2}{|c|}{1970 A\&AS 371} \\
\hline 334 & \multicolumn{3}{|l|}{ Muller $P$. } & \multicolumn{2}{|c|}{1970 A\&AS 1399} \\
\hline 338 & \multicolumn{3}{|l|}{ Baize P. } & \multicolumn{2}{|c|}{1972 A\&AS 6147} \\
\hline 340 & Couteau P. & & & $1972 \mathrm{~A} \&$ & S 6185 \\
\hline 346 & Worley C. E. & & & $1972 \mathrm{PU}$ & $\mathrm{NO} 224$ \\
\hline
\end{tabular}

Fig. 5. Web page obtained by querying SIDONIE for references for COU 14.

interrogation on SIDONIE on the measurements of the star COU 14.

The result of the queries on published orbits is shown in Fig. 4

Figure 5 gives an example of the file extracted from references on the measurements of COU14.

Interrogating SIDONIE can also give access to statistical results. Conceived as a tool to help with the preparation of observation programs, this mode of interrogation permits the selection of a group of objects in relationship to multiple pertinent criteria related to identifications, magnitudes, spectral type and measurements.

Figure 6 illustrates the statistical mode of interrogation. It gives a list of double stars discovered by $\mathrm{P}$. Couteau (named COU) having numbers in the HIPPARCOS Catalog (HIP) with right ascensions

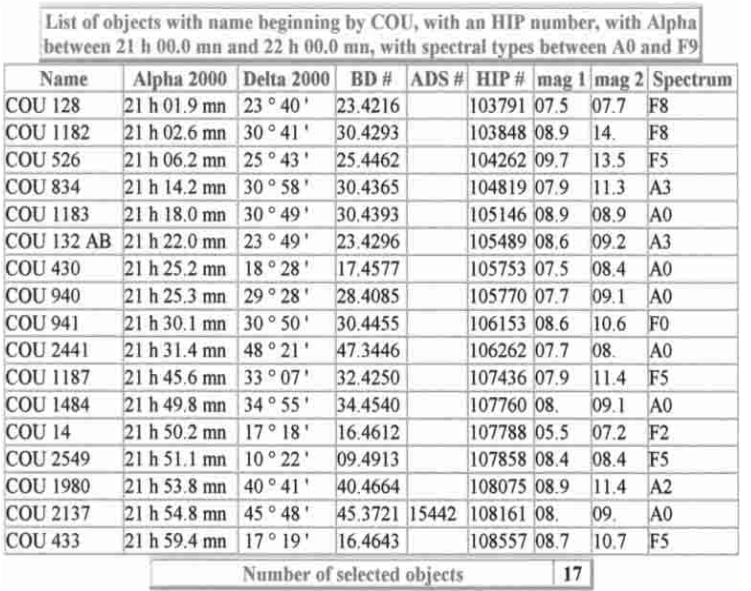

Fig. 6. Web page obtained by querying SIDONIE for statistical data (see text).

between 21.00 and 22.00 hours and with the spectral type of the primary star between A0 and F9.

The contents of the SIDONIE database will be regularly updated by adding new published measurements.

\section{Conclusion}

Numerous research projects concerning stellar and galactic evolution rely on the determination of fundamental physical parameters or the nature of statistical results of the observation of double stars. In fact, it has been stated that the study of double stars benefits the development of modern observational techniques such as speckle interferometry, CCD imaging and adaptive optics. SIDONIE, by its very specificity, makes an effective tool for researchers involved in the preparation of observation programs, the calculation of orbits or the histories of double stars. Observers are encouraged not only to consult and use SIDONIE, but also to communicate their remarks as well as the results of their measurements to help constantly improve and update the database.

Acknowledgements. We would like to thank P. Couteau, A. Endignoux, P. De Laverny, P. Mathias, J.C. Thorel, E. CueniLupo, the responsible staffs of the O.C.A. and of the INSU for having, all of them, worked towards SIDONIE's existence.

\section{References}

Hartkopf, W. I., McAlister, H., \& Mason, B. D. 2000, in CHARA Contribution, 4

Worley, C. E., \& Douglass, G. G. 1997, A\&AS, 125, 523 